\title{
Automated Sample Multiplexing by using Combined Precursor Isotopic Labeling and Isobaric Tagging (cPILOT)
}

\author{
Albert B. Arul ${ }^{1}$, Renã A.S. Robinson ${ }^{1,2,3,4}$ \\ ${ }^{1}$ Department of Chemistry, Vanderbilt University ${ }^{2}$ Vanderbilt Memory \& Alzheimer's Center, Vanderbilt University Medical Center ${ }^{3}$ Vanderbilt Brain \\ Institute, Vanderbilt University Medical Center ${ }^{4}$ Vanderbilt Institute of Chemical Biology, Vanderbilt University Medical Center
}

\section{Corresponding Author}

Renã A.S. Robinson

rena.as.robinson@vanderbilt.edu

\section{Citation}

Arul, A.B., Robinson, R.A. Automated Sample Multiplexing by using Combined Precursor Isotopic Labeling and Isobaric Tagging (cPILOT). J. Vis. Exp. (166), e61342, doi:10.3791/61342 (2020).

\section{Date Published}

December 18, 2020

DOI

$10.3791 / 61342$

URL

jove.com/video/61342

\section{Abstract}

We have introduced a high throughput quantitative proteomics workflow, combined precursor isotopic labeling and isobaric tagging (cPILOT) capable of multiplexing up to 22 or 24 samples with tandem mass tags or isobaric N,N-dimethyl leucine isobaric tags, respectively, in a single experiment. This enhanced sample multiplexing considerably reduces mass spectrometry acquisition times and increases the utility of the expensive commercial isobaric reagents. However, the manual process of sample handling and pipetting steps in the strategy can be labor intensive, time consuming, and introduce sample loss and quantitative error. These limitations can be overcome through the incorporation of automation. Here we transferred the manual cPILOT protocol to an automated liquid handling device that can prepare large sample numbers (i.e., 96 samples) in parallel. Overall, automation increases feasibility and reproducibility of cPILOT and allows for broad usage by other researchers with comparable automation devices.

\section{Introduction}

Mass spectrometry (MS)-based proteomics is an indispensable research tool in identifying disease specific biomarkers, understanding disease progression, and creating leads for therapeutic development. This can be achieved from a range of disease-related clinical samples such as blood serum/plasma, proximal fluids, and tissues ${ }^{1,2}$. Proteomics biomarker discovery and validation have recently gained significant consideration due to the power of sample multiplexing strategies ${ }^{3,4}$. Sample multiplexing is a technique that enables simultaneous comparison and quantification of two or more sample conditions within a single MS injection ${ }^{5,6}$. Sample multiplexing is achieved by barcoding peptides or proteins from multiple samples with chemical, enzymatic, or metabolic tags and obtaining MS information from all samples in a single MS or MS/MS experiment. Among the available isobaric tags are isobaric tagging reagents (iTRAQ), commercial tandem mass tags (TMT), and in house 
synthesized isobaric N,N-dimethyl leucine (DiLeu) reagents with capabilities up to $16-$ plex $^{7}$ and $21-$ plex $^{8}$, respectively.

Combined precursor isotopic labeling and isobaric tagging (cPILOT) is an enhanced sample multiplexing technology. cPILOT combines isotopic labeling of peptide $\mathrm{N}$-termini with light $\left[-\left(\mathrm{CH}_{3}\right)_{2}\right]$ and heavy $\left[-\left({ }^{13} \mathrm{C}^{2} \mathrm{H}_{3}\right)_{2}\right]$ isotopes at low $\mathrm{pH}$ (\#2.5), which keeps the lysine residue available for subsequent high $\mathrm{pH}$ (8.5) isobaric labeling using TMT, DiLeu, or iTRAQ tagging $3,9,10,11,12,13,14$. The dual labeling scheme of the cPILOT strategy is depicted in Supplemental Figure 1 with two samples using an example peptide. The accuracy and precision of the TMT based quantification at the $\mathrm{MS}^{2}$ level can be compromised due to the presence of contaminating co-isolated and co-fragmented ions termed as the interference effect ${ }^{15}$. This limitation in inaccurate reporter ion ratios can be overcome with the help of tribrid Orbitrap mass spectrometers. For example, the interference effect can be overcome by isolating a peak in a dimethylated pair at the $\mathrm{MS}^{1}$ level in the mass spectrometer, subjecting the light or heavy peak to $\mathrm{MS}^{2}$ fragmentation in the linear ion trap and then subjecting the most intense $\mathrm{MS}^{2}$ fragment for HCD-MS ${ }^{3}$ to obtain quantitative information. In order to increase the chances of selecting the peptides without lysine amines available for generating reporter ions, a selective $\mathrm{MS}^{3}$ acquisition based on the $y-1$ fragment also can be used and is an approach which can result in a higher percentage of peptides quantifiable with $\mathrm{CPILOT}^{9}$. The combination of light and heavy labeling increases sample multiplexing capabilities by a factor of $2 x$ to that achieved with individual isobaric tags. We have recently used cPILOT to combine up to 24 samples in a single experiment with DiLeu reagents ${ }^{16}$. Additionally cPILOT has been used to study oxidative posttranslational modifications ${ }^{14}$ including protein nitration ${ }^{17}$, other global proteomes ${ }^{9}$, and has demonstrated applications across multiple tissue samples in an Alzheimer's disease mouse model ${ }^{11}$.

Robust sample preparation is a critical step in a cPILOT experiment and can be time-consuming, laborious, and extensive. Enhanced sample multiplexing requires extensive pipetting and highly skilled laboratory personnel, and there are several factors that can heavily influence the reproducibility of the experiment. For example, careful handling of samples is necessary to ensure similar reaction times for all samples and to maintain appropriate buffer $\mathrm{pH}$ for light and heavy dimethylated samples. Furthermore, manual preparation of tens to hundreds of samples can introduce high experimental error. Therefore, to reduce sample preparation variability, improve quantitative accuracy, and increase experimental throughput, we developed an automated cPILOT workflow. Automation is achieved using a robotic liquid handling device that can complete many aspects of the workflow (Figure 1). Sample preparation from protein quantification to peptide labeling was performed on an automated liquid handler. The automated liquid handler is integrated with a positive pressure apparatus (PPA) for buffer exchanges between the solid-phase extraction (SPE) plates, orbital shaker, and a heating/cooling device. The robotic platform contains 28 deck locations to accommodate plates and buffers. There are two pods with a gripper to transfer the plates within the deck locations: a 96-channel fixed volume pipetting head (5-1100 $\mu \mathrm{L})$ and 8 channel variable volume probes $(1-1000 \mu \mathrm{L})$. The robotic platform is controlled using a software. The user needs to be professionally trained prior to using the robotic liquid handler. The present study focuses on automating the manual cPILOT workflow, which can be labor intensive for processing more than 12 samples in a single batch. In order to increase the throughput of the cPILOT approach ${ }^{11}$, we transferred the CPILOT protocol to 
a robotic liquid handler to process more than 10 samples in parallel. The automation also allows similar reactions for each sample in parallel during various steps of the sample preparation process, which required highly trained users to achieve during manual cPILOT. This protocol focuses on the implementation of the automated liquid handling device to carry out CPILOT. The present study describes the protocol for using this automated system and demonstrates its performance using a 22-plex "proof-of-concept" analysis of mouse liver homogenates.

\section{Protocol}

All animal protocols were approved by the Institutional Animal Care and Use Committee at the University of Pittsburgh. One male control mouse (C57/BLJ) was purchased commercially and housed in the Division of Laboratory Animal Resources at the University of Pittsburgh. Mice were fed standard rodent laboratory chow ad libitum and kept in a $12 \mathrm{~h}$ light/dark cycle. Liver tissue was harvested and stored at $-80^{\circ} \mathrm{C}$.

\section{Protein extraction}

NOTE: These steps are performed manually.

1. Wash mouse liver $(100 \mathrm{mg})$ with saline and homogenate with $500 \mu \mathrm{L}$ of $8 \mathrm{M}$ urea using a mechanical homogenizer using lysing matrix $A$ beads for $4 \mathrm{~m} / \mathrm{s}$ for $20 \mathrm{~s}$.

NOTE: In this study, protease or phosphatase inhibitors were not added but may be added to the buffer if necessary, based on the experiment. Also, protein extraction steps can be adjusted accordingly for various sample types.

2. Transfer the tissue homogenate to a new microcentrifuge tube, rinse and combine the lysing tubes with $100-500 \mu \mathrm{L}$ of PBS with $8 \mathrm{M}$ urea.
3. Centrifuge the homogenized tissues $\left(12,800 \times \mathrm{g}, 4^{\circ} \mathrm{C}\right.$, and $15 \mathrm{~min}$ ) and collect the supernatant.

NOTE: The rest of the steps are carried out on the robotic liquid handler available in the user's laboratory. The liquid handler must be capable of aspirating and dispensing buffers from and to ANCl specified plate's types, with minimal operator participation.

4. Determine the protein concentration using a bicinchoninic acid (BCA) assay according to manufacturer's instructions.

5. Turn on the PPA, heating/cooling device, and the vacuum pumps and connect all the accessories with liquid handler. The liquid handler shows a blue light once it is connected to the computer and ready to operate.

6. To reagent plate 1 (96 well plate), add $30 \mu \mathrm{L}$ of $25 \mathrm{mM}$ 1,4-dithiothreitol (DTT), $25 \mathrm{mM} 30 \mu \mathrm{L}$ of cysteine and 25 $\mathrm{mM} 30 \mu \mathrm{L}$ of iodoacetamide (IAA) to rows 1,2 , and 3 , respectively.

7. Add $8 \mathrm{M}$ urea and $20 \mathrm{mM}$ Tris with $10 \mathrm{mM} \mathrm{CaCl}_{2}(\mathrm{pH} 8.2)$ to a reservoir plate. Add $500 \mu \mathrm{L}$ of $5 \%$ formic acid to 2 $\mathrm{mL}$ deep well plate, $20 \mu \mathrm{L}$ of trypsin to row 1 of trypsin plate and place in the deck location as specified by the method.

NOTE: IAA and trypsin were added to the 96 well plate prior to adding to the sample.

8. Aliquot $300 \mu \mathrm{L}$ of the liver homogenate into a 500 $\mu \mathrm{L}$ tube and place on a $2 \mathrm{~mL}$ deep well plate and place at $4{ }^{\circ} \mathrm{C}$ until the start of the protocol. For this experiment, 22 aliquots were generated from the single liver homogenate.

NOTE: Add an internal quality control standard (e.g., bovine alpha casein or other exogenous protein) with the ratio $1 \mu \mathrm{g}$ standard: $100 \mu \mathrm{g}$ protein sample. 
9. Define the volume of buffers to be added to the samples by variable names and value as per Table 1. Based on the $\mathrm{BCA}$, enter the volume of sample and normalization buffer ( $8 \mathrm{M}$ urea) on a spreadsheet and attach to the software (Table 2).

NOTE: Further dilution with buffer may be necessary if the protein concentration is too high. The resulting concentrations for sample from the liver tissue was 10 $\mu \mathrm{g} / \mu \mathrm{L}$. The volume of buffers was optimized for $100 \mu \mathrm{g}$ protein.

10. Remove sample tubes from $4{ }^{\circ} \mathrm{C}$, place on the specified deck location of the automated liquid handler, and allow to warm for $10 \mathrm{~min}$.

11. Open the method and follow the instructions to place the required tips $(1070,90$, and $230 \mu \mathrm{L})$, and labware into the desired positions. Once all the labware and tips are in place, cross check with the final deck layout and click Next to continue the protocol.

NOTE: The guided set up informs the user to add a required volume of buffer to the specific labware depending on the protocol and the deck location to be kept.

\section{Sample reduction, alkylation and digestion}

1. Load $230 \mu \mathrm{L}$ tips and aspirate $90 \mu \mathrm{L}$ of $8 \mathrm{M}$ urea from the reservoir and dispense to row 1 of the black $2 \mathrm{~mL}$ deep well plate. Unload the tips. Repeat this step until $8 \mathrm{M}$ urea is added to all the wells corresponding to the 22 samples. NOTE: The denaturation buffer unwinds the protein three-dimensional structure to yield the primary structure so the trypsin can act and break the protein effectively. The 8-channel pipette can aspirate different volumes for the 8 channels and can dispense to different locations in the labware. In this step all the channels aspirated the same volume as defined in the software.

2. After adding the denaturation buffer, load the $90 \mu \mathrm{L}$ tips and aspirate $10 \mu \mathrm{L}$ (corresponds to $100 \mu \mathrm{g}$ ) of mouse liver homogenate using the 8-channel pipette to the black $2 \mathrm{~mL}$ deep well plate. Unload the tips. Repeat this step until all the 22 samples are transferred.

3. After each transfer, perform a mix step to aspirate and dispense $50 \mu \mathrm{L}$ of the well contents thrice to ensure mixing of the protein with the buffer to exhibit a 1:1 ratio. NOTE: Remove stock homogenate sample and place in $-80^{\circ} \mathrm{C}$.

4. To reduce the denatured proteins, load one row of $90 \mu \mathrm{L}$ tips and aspirate $3 \mu \mathrm{L}$ of DTT from the reagent plate 1 . Dispense DTT to rows 1 and 2 of the black $2 \mathrm{~mL}$ deep well plate and unload the tips.

NOTE: The protein: DTT molar ratio is maintained at 1:40 for reduction of disulfide bonds. The calculation for the molar ratio is based off the protein mass of bovine serum albumin (BSA), which is $66.5 \times 10^{3} \mathrm{~g} / \mathrm{mol}$.

5. Seal the sample plate with aluminum foil and incubate at $37^{\circ} \mathrm{C}$ for $600 \mathrm{~s}$ at $300 \mathrm{rpm}$.

6. Add $30 \mu \mathrm{L}$ of $0.25 \mathrm{M}$ IAM to row 3 of reagent plate 1 just before use and place on the deck. Unseal the sample plate and return to the deck.

NOTE: IAM is light sensitive.

7. Load one row of $90 \mu \mathrm{L}$ tips, aspirate $6 \mu \mathrm{L}$ of IAM from the reagent plate 1 at row 3 , and dispense to row 1 of the sample plate. Unload the tips.

NOTE: The protein: IAM molar ratio is maintained at 1:80 for each sample. This reaction must be done in the dark.

8. Seal the sample plate and incubate at $4{ }^{\circ} \mathrm{C}$ for $30 \mathrm{~min}$ at $300 \mathrm{rpm}$ on the heating/cooling device. 
NOTE: Sealing the plate is performed to prevent the sample from light, evaporation and spilling from the well.

9. Unseal the sample plate and load one row of $90 \mu \mathrm{L}$ tips and aspirate $5 \mu \mathrm{L}$ of cysteine from the reagent plate 1 at row 2 . Dispense to rows 1 and 2 of the sample plate and unload the tips. Incubate at room temperature for $30 \mathrm{~min}$. NOTE: The protein: L-cysteine molar ratio is maintained at $1: 40$.

10. Place the sample plate on the orbital shaker to perform a timed shake of $1800 \mathrm{rpm}$ for $30 \mathrm{~min}$.

11. Add $800 \mu \mathrm{L}$ of $20 \mathrm{mM}$ Tris buffer with $10 \mathrm{mM} \mathrm{CaCl}_{2}(\mathrm{pH}$ 8.2) to each well of the sample plate to dilute the urea concentration to $2 \mathrm{M}$. Unload the tips.

NOTE: Trypsin activity is hindered at higher urea concentrations and hence it must be reduced to less than $2 \mathrm{M}$. This study was performed with a protein to trypsin molar ratio of 50: 1 for $14 \mathrm{~h}$.

12. Add $20 \mu \mathrm{L}$ of trypsin to row 1 , column $1-12$ of a 96 well plate and place at a specified location on the deck.

13. Load one row of $90 \mu \mathrm{L}$ tips, aspirate $2 \mu \mathrm{L}$ of trypsin from the trypsin plate row 1 , and dispense to rows 1 and 2 of the sample plate. Unload the tips.

14. Seal the plate and incubate for $14 \mathrm{~h}$ at $37^{\circ} \mathrm{C}$ at $600 \mathrm{rpm}$ on the heating/cooling device.

15. After incubation, unseal the sample plate and add $5 \%$ formic acid to row 3, column 1- 12 of a deep well collection plate and place it on specified deck.

16. Stop the digestion by adding $150 \mu \mathrm{L}$ of $5 \%$ formic acid from row 3 of the formic acid plate and dispense to sample plate at rows 1 and 2 . Unload the tips.

\section{Desalting step 1}

1. Desalt the peptides with SPE plate containing $20 \mathrm{mg}$ of Targa C-18 material. Fix the volume for every buffer exchange as $600 \mu \mathrm{L}$ and fix the pressure to $100 \mathrm{mbar}$.

2. Load $1070 \mu \mathrm{L}$ tips and aspirate $600 \mu \mathrm{L}$ of acetonitrile and dispense to rows 1 and 2 of SPE plate. Place the SPE plate on PPA and apply pressure.

3. Using the same tips, aspirate $600 \mu \mathrm{L}$ of acetonitrile and dispense to rows 1 and 2 of SPE plate. Place the SPE plate on PPA and apply pressure.

NOTE: The flow-through can be drained to waste using a suction pump.

4. Load $1070 \mu \mathrm{L}$ tips and aspirate $600 \mu \mathrm{L}$ of Buffer $\mathrm{A}(100$ $\%$ water in $0.1 \%$ formic acid) and dispense to rows 1 and 2 of SPE plate. Place the SPE plate on PPA and apply pressure.

NOTE: If the volume of the buffer does not reduce significantly try increasing the pressure or time.

5. Load 2 rows of $1070 \mu \mathrm{L}$ tips, aspirate $534 \mu \mathrm{L}$ of digested samples, and dispense to rows 1 and 2 of SPE plate. Place the SPE plate on PPA and apply pressure. Repeat this step until all the samples are loaded.

NOTE: Since the total volume after adding formic acid will be $1068 \mu \mathrm{L}$ and the samples were added in two passes.

6. Load 2 rows of used $1070 \mu \mathrm{L}$ tips, aspirate $600 \mu \mathrm{L}$ of Buffer A, and dispense to rows 1 and 2 of SPE plate. Place the SPE plate on PPA and apply pressure.

7. Repeat the above step once to clean the sample.

8. Load 1 row of $1070 \mu \mathrm{L}$ tips, aspirate $600 \mu \mathrm{L}$ of $\mathrm{ACN}$ : Water (60:40) and dispense to rows 1 and 2 of SPE plate. Place the SPE plate on top of a collection plate to elute the peptides using PPA and apply pressure. 
9. Repeat the above step to elute the peptides in the collection plate. Dry the collection plate to dryness and store at $-80^{\circ} \mathrm{C}$ until further processing.

\section{Dimethylation Labeling (peptide $\mathbf{N}$-termini)}

1. Place the required tips $(1070,90$, and $230 \mu \mathrm{L})$, and labware into the desired positions in the software. Once all the labware and tips are in place, cross check with the final deck layout and click Next to continue the protocol.

2. To reagent plate 2 , add $450 \mu \mathrm{L}$ of $1 \%$ acetic acid, $50 \mu \mathrm{L}$ light formaldehyde $\left(\mathrm{CH}_{2} \mathrm{O}\right), 50 \mu \mathrm{L}$ of heavy formaldehyde $\left({ }^{13} \mathrm{CD}_{2} \mathrm{O}\right)$, and $150 \mu \mathrm{L}$ of formic acid to rows $1,2,3$ and 4 respectively.

3. To reagent plate 3 add $50 \mu \mathrm{L}$ of light $\mathrm{CB}, 50 \mu \mathrm{L}$ of heavy CB, to rows 1 and 2 and $50 \mu \mathrm{L}$ of Ammonia to row 3 and 4 .

4. Load 2 rows of $230 \mu \mathrm{L}$ tips and aspirate $100 \mu \mathrm{L}$ of $1 \%$ acetic acid from row 1 of reagent plate 2 and dispense to the dried down peptides in sample plate 2 (collection plate from the desalting step) rows 1 and 2 and perform a timed shaking for $5 \mathrm{~min}$ at $1800 \mathrm{rpm}$.

5. Load $90 \mu \mathrm{L}$ tips and aspirate $16 \mu \mathrm{L}$ of $60 \mathrm{mM}(4 \%) \mathrm{CH}_{2} \mathrm{O}$ $(37 \% \mathrm{wt} / \mathrm{v})$ from row 2 of reagent plate 2 and dispense to row 1 of the sample plate. Unload the tips.

6. Load 1 row of $90 \mu \mathrm{L}$ tips and aspirate $16 \mu \mathrm{L}$ of $60 \mathrm{mM}$ $(4 \%){ }^{13} \mathrm{CD}_{2} \mathrm{O}(20 \% \mathrm{wt} / \mathrm{v})$ from row 3 of reagent plate 2 and dispense to row 2 of the sample plate. Unload the tips.

NOTE: In this study row 1 corresponds to light and row 2 corresponds to heavy dimethylated samples (See Figure 1).

7. Load 2 rows of $90 \mu \mathrm{L}$ tips and aspirate $16 \mu \mathrm{L}$ of 24 $\mathrm{mM} \mathrm{NaBH} \mathrm{N}_{3} \mathrm{CN}$ and $24 \mathrm{mM} \mathrm{NaBD}{ }_{3} \mathrm{CN}$ from row 1 and
2 of reagent plate 3 and dispense to rows 1 and 2, respectively of the sample plate.

8. Unload the tips and perform a timed shake for $15 \mathrm{~min}$ at 1800 rpm using the orbital shaker.

NOTE: Adding sodium cyanoborohydride initiates the reaction hence to reduce variability between experiments this step is performed once per batch.

9. Load 2 row of $90 \mu \mathrm{L}$ tips and aspirate $32 \mu \mathrm{L}$ of $1 \%$ ammonia $(\sim 28-30 \% \mathrm{v} / \mathrm{v})$ from rows 3 and 4 of reagent plate 3 and dispense to rows 1 and 2 respectively of the sample plate 2 . Unload the tips.

NOTE: Adding ammonia stops the reaction hence to reduce variability between experiments this step is performed once per batch.

10. Combine equal volumes of light and heavy (1:1) dimethylated peptides to a new $2 \mathrm{~mL}$ deep well plate for desalting.

NOTE: In this study $90 \mu \mathrm{L}$ of the well contents from row 1 was combined with $90 \mu \mathrm{L}$ of row 2 from sample plate 2 to a new $2 \mathrm{~mL}$ collection plate (Sample Plate 3 ). The ratio of light: heavy mixing depends on the experimental protocol, in this study a 1:1 ratio was used.

11. Load 2 rows of $230 \mu \mathrm{L}$ tips and aspirate $32 \mu \mathrm{L}$ of $5 \%$ formic acid to the combined samples and perform a timed shaking for $30 \mathrm{~s}$ at $1800 \mathrm{rpm}$.

NOTE: The dimethylation efficiency depends on the $\mathrm{pH}$ of the reaction mixture and any change in buffer $\mathrm{pH}$ will result in incomplete labeling of the peptide $\mathrm{N}$-termini. Dimethylation efficiency should be greater than $97 \%$ when searched as dynamic modification at the peptide $\mathrm{N}$-termini. In this study the labeling efficiency of light and heavy peptides were $99.7 \%$ and $99.5 \%$ respectively. 


\section{Desalting step 2}

1. Perform sample desalting similar to the desalt step 1 for the combined samples.

2. Dry the samples in the sample plate using a speed vac and store at $-80{ }^{\circ} \mathrm{C}$ until further processing.

\section{Isobaric tagging (Lys residues)}

1. Follow the guided labware setup and place the required tips $(1070,90$, and $230 \mu \mathrm{L})$, with appropriate buffers. Once all the labware and tips are in place, cross check with the final deck layout and click Next to continue the protocol.

2. Add $250 \mu \mathrm{L}$ of $100 \mathrm{mM}$ triethyl ammonium bicarbonate (TEAB), $30 \mu \mathrm{L}$ of hydroxylamine $(10 \% \mathrm{w} / \mathrm{v})$ to rows 1 , and 2 of reagent plate 4. Place the TMT tubes on the $2 \mathrm{~mL}$ deep-well plate as per the spreadsheet in Table 3.

3. Keep an empty $1.5 \mathrm{~mL}$ tube in a tube rack holder for pooling the tagged peptides. Place the dried down sample plate at P9 and TMT processing plate at P14.

4. To reconstitute the peptides, load $230 \mu \mathrm{L}$ tips and aspirate $100 \mu \mathrm{L}$ of $100 \mathrm{mM}$ triethyl ammonium bicarbonate (TEAB) buffer ( $\mathrm{pH} \sim 8.5$ ) from row 1 at TEAB plate and dispense to the dried peptides at row 3 of sample plate 3 . Place the plate on the orbital shaker for $30 \mathrm{~s}$ at $1800 \mathrm{rpm}$.

NOTE: Reconstitute $100 \mu \mathrm{g}$ of dimethylated peptides at a concentration of $1 \mu \mathrm{g} / \mu \mathrm{L}$.

5. Load $90 \mu \mathrm{L}$ tips and aspirate $10 \mu \mathrm{L}$ of anhydrous acetonitrile from $\mathrm{H} 12$ of the TMT plate and dispense into each of the dried TMT tubes.

6. Remove the TMT tubes, vortex, and quick spin the tubes and return to deck in deep well plate.
7. Load 1 row of $90 \mu \mathrm{L}$ tips and aspirate $12.5 \mu \mathrm{L}$ of the combined dimethylated peptides and dispense to the row 1 of the TMT processing plate. Unload the tips.

NOTE: The TMT: peptide ratio was maintained at 1:8 for this experiment.

8. Load 1 row of $90 \mu \mathrm{L}$ tips and aspirate $10 \mu \mathrm{L}$ of TMT and dispense to the row 1 of the TMT processing plate. Unload the tips, perform a timed shake for 1 hour at 1800 rpm.

9. Load 1 row of $90 \mu \mathrm{L}$ tips and aspirate $8 \mu \mathrm{L}$ of hydroxylamine $(10 \% \mathrm{w} / \mathrm{v})$ from row 2 at TEAB plate and dispense to the row 1 of the TMT processing plate. Unload the tips, perform a timed shaking for $15 \mathrm{~min}$ at $1800 \mathrm{rpm}$.

10. Combine $30.5 \mu \mathrm{L}$ of the TMT labeled peptides from TMT processing plate to $1.5 \mathrm{~mL}$ tube. Unload the tips after each transfer.

11. Remove the tube with the pooled samples and dry to evaporate the acetonitrile. Reconstitute peptides in 0.2 $\mathrm{mL}$ of water in $0.1 \%$ formic acid and return to the deck. NOTE: The labeling efficiency of isobaric tagging is also $\mathrm{pH}$ specific and the labeling efficiency should be above $98 \%$ per manufacturer's instructions. In this study the TMT labeling efficiency of the lysine terminated light and heavy peptides was $99.4 \%$ and $99.5 \%$ respectively.

\section{Desalting step}

1. Perform sample desalting similar to the desalt 1 for one sample.

2. Dry the samples and store in $-80^{\circ} \mathrm{C}$ until analysis. 


\section{Liquid Chromatography-Tandem Mass Spectrometry (LC-MS/MS) and MS $^{3}$}

1. Reconstitute the peptides in MS grade water with $0.1 \%$ FA to obtain $\sim 1 \mu \mathrm{g} / \mu \mathrm{L}$ concentration. Filter samples with microcentrifuge tubes containing a $0.65 \mu \mathrm{m}$ filter. Centrifuge peptides at $12,000 \times \mathrm{g}$ for $3 \mathrm{~min}$ and place the flow through into an auto-sampler vial.

NOTE: The peptide concentration can be confirmed at this stage if desired. The peptides would need to be reconstituted in LC-MS grade water and subject to a BCA peptide assay. In this study, the peptide BCA assay was not performed and all peptide amounts were based on initial protein BCA assay.

2. Prepare the mobile phase buffers as follows: $100 \%(\mathrm{v} / \mathrm{v})$ water with $0.1 \% \mathrm{FA}(\mathrm{A})$ and $100 \% \mathrm{ACN}$ with $0.1 \% \mathrm{FA}(\mathrm{B})$.

3. Inject $1 \mu \mathrm{L}$ of sample onto a trap column packed with 2 $\mathrm{cm}$ of $\mathrm{C}_{18}$ material $(3 \mu \mathrm{m}, 100 \AA$ pore size).

NOTE: Sample cleaning on the trap is as follows: 10 min, $100 \% A ; 2 \mu \mathrm{L} /$ min using a $2 \mathrm{D}$ liquid chromatography system.

4. Run the analytical separation method. Use a $100 \mu \mathrm{m}$ i.d. x $26 \mathrm{~cm}$ laser pulled-tip fused silica capillary column packed with $\mathrm{C}_{18}$ material $(2.5 \mu \mathrm{m}, 100 \AA)$. The gradient is: $0-10 \mathrm{~min}, 10 \% \mathrm{~B} ; 10-30 \mathrm{~min}, 10-15 \% \mathrm{~B} ; 30-75 \mathrm{~min}$, $15-30 \%$ B; $75-88$ min, $30-60 \%$ B; 88-92 min, 60-90\% B; 92-99 min, 90\% B; 99-100 min, 90-10\% B, 100-120 min, $10 \% \mathrm{~B} ; 300 \mathrm{~nL} / \mathrm{min}, 120 \mathrm{~min}$.

5. Run the data acquisition for the mass spectrometer while the analytical separation method is running.

1. Use the following parameters for the MS survey scan: $375-1,500 \mathrm{~m} / \mathrm{z}, 120,000$ resolution, Cycle time
$3 \mathrm{~s}$ (top speed), automatic gain control (AGC) target 4.0e5, maximum injection time $50 \mathrm{~ms}$.

2. Use the following parameters for CID-MS/MS with ion trap: data dependent acquisition (DDA) scans per outcome, $2 \mathrm{~m} / \mathrm{z}$ isolation width, $35 \%$ normalized collision energy (NCE), 0.25 activation q, $10 \mathrm{~ms}$ activation time, 1.0e4 AGC, $100 \mathrm{~ms}$ maximum injection time.

3. Use the following parameters for HCD-MS3 SPS 10: Scan range $100-400 \mathrm{~m} / \mathrm{z}$, number of dependent scans 10, AGC 5.0e4, maximum injection time $118 \mathrm{~ms}$, HCD collision energy $55 \%, \mathrm{MS}^{2}$ isolation window 2.

\section{Data analysis}

1. Search generated RAW files for the list of proteins and peptides using a protein analysis software against an appropriate database.

NOTE: The RAW files generated in this study were searched against a mouse Uniprot database.

2. Since there is both light and heavy labeling in one RAW file, search each file with two workflows for light and heavy dimethylated peptides.

3. Search the RAW files against mouse Uniprot database (07/13/2019) with 53035 sequence with the following parameters: trypsin cleavage with maximum two missed cleavages, peptide with minimum 6 amino acids length, $15 \mathrm{ppm}$ parent mass tolerance, $1 \mathrm{Da}$ fragmentation tolerance Static modifications: light dimethylation (+28.031, peptide $\mathrm{N}$-terminus) or heavy dimethylation (+36.076 Da, peptide N-terminus), carbamidomethyl $(+57.021 \mathrm{Da}, \mathrm{C})$, Dynamic modifications: oxidation (+15.995 Da, M), 11-plex isobaric tag (229.163 Da, 
$\mathrm{K}), 1 \% \mathrm{FDR}$, reporter ion quantification with $30 \mathrm{ppm}$ peak integration tolerance, most confident centroid for integration method.

NOTE: The heavy dimethylated peak also includes another modification which is $\sim 7 \mathrm{Da}(+35.069 \mathrm{Da}$, peptide $\mathrm{N}$-terminus) from the light dimethylated peak and therefore another search node should be incorporated to include this modification also.

4. Perform reporter ion quantification based on the intensity, $65 \%$ SPS mass match, average $\mathrm{S} / \mathrm{N}$ ratio 10 , isotopic correction, normalization and scaling were not performed.

NOTE: Normalization and scaling can be performed based on total peptide amount or a specific protein added to the sample. QC samples can also be included in the channels for inter-batch or intra-batch normalization based on a two-tailed internal reference scaling ${ }^{18}$. The isotopic contaminations of different TMT channels were not provided to the search, users are advised to add the isotope contamination of different reporter ions.

\section{Representative Results}

Figure 2 shows representative MS data of a peptide identified in all 22 reporter ion channels from a 22-plex cPILOT experiment, including workflow replicates. Figure 2 (top) depicts a doubly charged peak pair separated by $4 \mathrm{Da} \mathrm{m} /$ $z$ spacing indicating a single dimethyl group incorporated into the peptide. The light and heavy dimethylated peak pairs were isolated and fragmented independently to yield the sequence of the peptide. The sequence of the peptide is $\mathrm{G}$ (dimethyl)AAELMQQK(TMT-11plex) and corresponds to the protein Betaine-homocysteine S-methyl transferase. The most intense fragment ions for both the light and heavy dimethylated peaks (not shown) were further isolated for $\mathrm{MS}^{3}$ fragmentation and the reporter ions $(m / z$ 126-131) are shown in Figure 2 (bottom). The reporter ion intensities are directly proportionate to the peptide abundance in the sample. The peptide abundance of the samples implies the pipetting ability of the robotic platform is fairly uniform across the 22 samples. Overall, this 22-plex cPILOT experiment resulted in 1326 (1209-light/1181-heavy) proteins identifications resulting from 3098 (6137-light/5872-heavy) peptides (Table 4). Figure 3 shows the box plot of $\log 10$ abundance versus total reporter ion intensities across all the 22 channels showing lesser inter-well/inter-sample variability. Evaluation of the total automation was done by examining the error in reporter ion abundance across each protein in the 22 samples. Figure 4 shows that sample processing with the robotic platform resulted in very low CV values. Specifically, across the 3098 peptides identified the average $\mathrm{CV}$ in reporter ion abundance was $12.36 \%$ and $15.03 \%$ for light and heavy dimethylated peptides, respectively. Among these peptides 2032 of these peptides had reporter ion signal above the minimum threshold and were deemed quantifiable. 


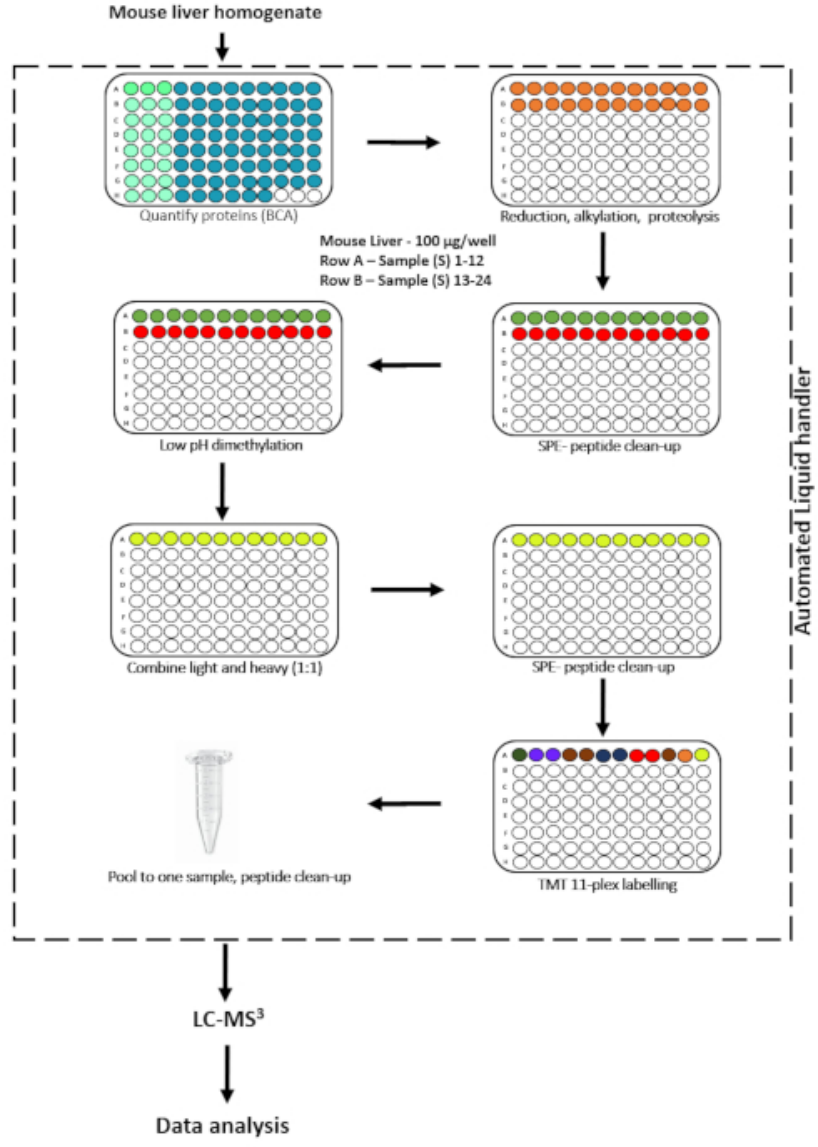

Figure 1. Experimental workflow to process 22 samples in parallel with an automated cPILOT protocol. Please click here to view a larger version of this figure. 


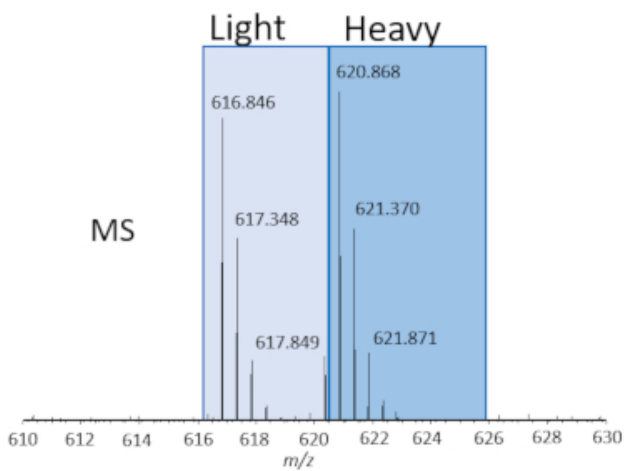

$\mathrm{MS} / \mathrm{MS}$

$\mathrm{MS}^{3}$

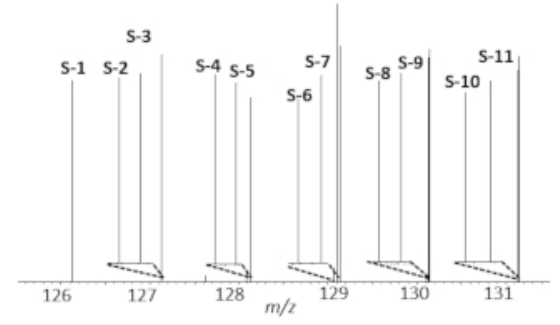

$\mathrm{MS}^{3}$

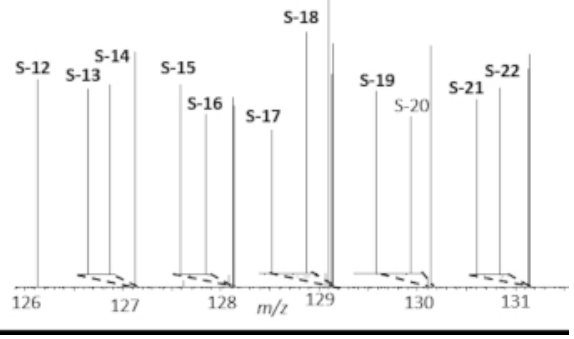

Figure 2. Quantification of peptides across 22 samples. Example MS (top) and $M S^{3}$ (bottom) spectra of the peptide G(dimethyl)AAELMQQK(TMT-11 plex) quantified in 22-plex automated cPILOT experiment for light dimethylated (bottom left) and heavy dimethylated (bottom right) peaks. Please click here to view a larger version of this figure. 


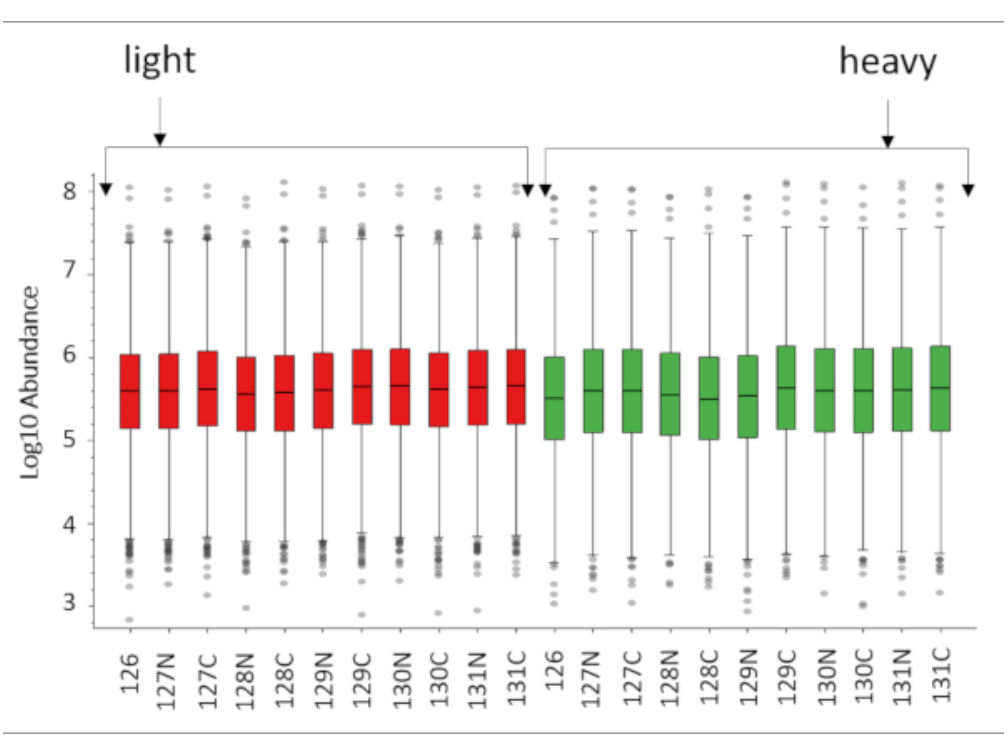

Figure 3. Box plot of total reporter ion intensities versus log10 abundance of 22 samples using proteome discoverer 2.3. The RAW file was searched twice for light and heavy peptides, proteins IDs separately with TMT as dynamic modification, light (+28.031 Da) and heavy (+36.076 \& +35.069 Da) dimethylation at peptide N-termini as static modification. A combined search with all the above modifications was run using Proteome Discover 2.3 to obtain the Log 10 Abundance of peptide intensities across all the channels. Please click here to view a larger version of this figure. 


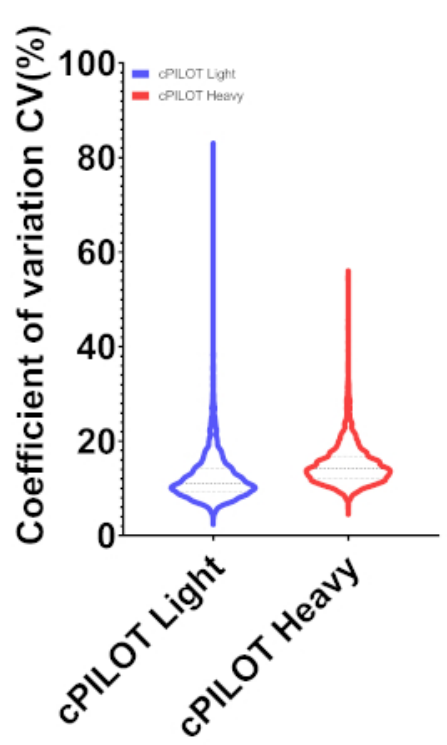

Figure 4. Violin plots of co-efficient of variation of peptide abundance from summed reporter ion intensities across channels $126-131 \mathrm{~m} / \mathrm{z}$. The peptide was quantified with an average CV value of 12.36 and 15.03 for light (2373) and heavy (2533) quantifiable peptides. Please click here to view a larger version of this figure.

Supplemental Figure 1. Illustration of the cPILOT with a mixture was injected to MS for LC-MS ${ }^{3}$. Please click here to single peptide. Showing the isotopic labeling of two different download this file. samples and isobaric tagging with $\mathrm{TMT}^{126}$, the resulting

\begin{tabular}{|c|c|c|}
\hline Variable Name & Value & Description \\
\hline DesaltSamp1 & 1065 & Volume to be used for desalt step 1 \\
\hline DesaltSamp2 & 392 & Volume to be used for desalt step 2 \\
\hline DesaltSamp3 & 100 & Volume to be used for desalt step 3 \\
\hline DevMode & FALSE & $\begin{array}{c}\text { False will cut-down the incubation } \\
\text { times to 30sec- True will follow the } \\
\text { incubation timing in the protocol. }\end{array}$ \\
\hline DTTVol & & Volume of DTT \\
\hline FilterPlate & 3 & Plate used for desalting \\
\hline FilterPlateVol & Targa & Volume for desalting \\
\hline
\end{tabular}




\begin{tabular}{|c|c|c|}
\hline HAWaterWashes & FALSE & $\begin{array}{c}\text { Number of water washes } \\
\text { on the SPE plate }\end{array}$ \\
\hline IAMVol & 2 & Volume of iodoacetamide \\
\hline PeptideTMTVol & 12.5 & Volume of peptide for TMT labelling \\
\hline pressure & 100 & mbar pressure at PPA \\
\hline TempOffSet & 1 & Change in temperature \\
\hline TMTVol & 10 & Isobaric tag volume to be added \\
\hline TrisVol & 800 & polume to dilute sample \\
\hline TrypsinVol & 2 & Volume of trypsin \\
\hline UsePopTimer & TRUE & pressure on plate if required \\
\hline
\end{tabular}

Table 1. List of variables used in automated cPILOT protocol. 


\begin{tabular}{|c|c|c|c|c|c|c|c|c|}
\hline DilSource & DilWell & Dest & DestWell & DilVolume & StockSource & StockWell & SampleVol & SampleID \\
\hline 8M_Urea & 1 & Samples & $\mathrm{A} 1$ & 90 & \$tock_Samples & $\mathrm{A} 1$ & 10 & 1 \\
\hline 8M_Urea & 1 & Samples & $\mathrm{A} 2$ & 90 & \$tock_Samples & $\mathrm{A} 1$ & 10 & 2 \\
\hline 8M_Urea & 1 & Samples & A3 & 90 & \$tock_Samples & $\mathrm{A} 1$ & 10 & 3 \\
\hline 8M_Urea & 1 & Samples & A4 & 90 & \$tock_Samples & A1 & 10 & 4 \\
\hline 8M_Urea & 1 & Samples & A5 & 90 & \$tock_Samples & $\mathrm{A} 1$ & 10 & 5 \\
\hline 8M_Urea & 1 & Samples & A6 & 90 & \$tock_Samples & $\mathrm{A} 1$ & 10 & 6 \\
\hline 8M_Urea & 1 & Samples & A7 & 90 & \$tock_Samples & A1 & 10 & 7 \\
\hline 8M_Urea & 1 & Samples & A8 & 90 & \$tock_Samples & A1 & 10 & 8 \\
\hline 8M_Urea & 1 & Samples & A9 & 90 & \$tock_Samples & A1 & 10 & 9 \\
\hline 8M_Urea & 1 & Samples & A10 & 90 & \$tock_Samples & A1 & 10 & 10 \\
\hline 8M_Urea & 1 & Samples & A11 & 90 & \$tock_Samples & A1 & 10 & 11 \\
\hline 8M_Urea & 1 & Samples & A12 & 90 & \$tock_Samples & $\mathrm{A} 1$ & 10 & 12 \\
\hline 8M_Urea & 1 & Samples & B1 & 90 & \$tock_Samples & A1 & 10 & 13 \\
\hline 8M_Urea & 1 & Samples & B2 & 90 & \$tock_Samples & $\mathrm{A} 1$ & 10 & 14 \\
\hline 8M_Urea & 1 & Samples & B3 & 90 & \$tock_Samples & $\mathrm{A} 1$ & 10 & 15 \\
\hline 8M_Urea & 1 & Samples & B4 & 90 & \$tock_Samples & $\mathrm{A} 1$ & 10 & 16 \\
\hline 8M_Urea & 1 & Samples & B5 & 90 & \$tock_Samples & $\mathrm{A} 1$ & 10 & 17 \\
\hline 8M_Urea & 1 & Samples & B6 & 90 & \$tock_Samples & $\mathrm{A} 1$ & 10 & 18 \\
\hline 8M_Urea & 1 & Samples & B7 & 90 & \$tock_Samples & $\mathrm{A} 1$ & 10 & 19 \\
\hline 8M_Urea & 1 & Samples & B8 & 90 & \$tock_Samples & A1 & 10 & 20 \\
\hline 8M_Urea & 1 & Samples & B9 & 90 & \$tock_Samples & $\mathrm{A} 1$ & 10 & 21 \\
\hline 8M_Urea & 1 & Samples & B10 & 90 & \$tock_Samples & $\mathrm{A} 1$ & 10 & 22 \\
\hline 8M_Urea & 1 & Samples & B11 & 90 & \$tock_Samples & $\mathrm{A} 1$ & 10 & 23 \\
\hline 8M_Urea & 1 & Samples & B12 & 90 & \$tock_Samples & $\mathrm{A} 1$ & 10 & 24 \\
\hline
\end{tabular}

Table 2. Volume of mouse liver homogenate and $8 \mathrm{M}$ urea. 


\begin{tabular}{|c|c|c|c|c|c|c|}
\hline SourceWell & SourceWell2 & Reporter lon & DestWell1 & DestWell2 & Volume & SampleID \\
\hline A1 & C1 & 126 & A1 & E1 & 10 & 1 \\
\hline A3 & C3 & $127 N$ & A2 & E2 & 10 & 2 \\
\hline A5 & C5 & $127 C$ & A3 & E3 & 10 & 3 \\
\hline A7 & C7 & $128 N$ & A4 & E4 & 10 & 4 \\
\hline A9 & C9 & $128 C$ & A5 & E5 & 10 & 5 \\
\hline A11 & C11 & $129 N$ & A6 & E6 & 10 & 6 \\
\hline B2 & D2 & $129 C$ & A7 & E7 & 10 & 7 \\
\hline B4 & D4 & $130 N$ & A8 & E8 & 10 & 8 \\
\hline B6 & D6 & $130 C$ & A9 & E9 & 10 & 9 \\
\hline B8 & D8 & $131 N$ & A10 & E10 & 10 & 10 \\
\hline B10 & D10 & $131 C$ & A11 & E11 & 10 & 11 \\
\hline
\end{tabular}

Table 3. Total number of peptides, proteins and peptide spectral matches (PSMs).

\begin{tabular}{|c|c|c|}
\hline & \multicolumn{2}{|c|}{ Automated cPILOT } \\
\hline & Light & 1181 \\
\hline Proteins & 1209 & 5872 \\
\hline Peptides & 6137 & 16762 \\
\hline PSMs & 14948 & Heavy \\
\hline
\end{tabular}

Table 4. Barcoding the isobaric tags with the light and heavy labelled samples.

\section{Discussion}

cPILOT is an enhanced multiplexing strategy that can analyze up to 24 samples in a single experiment. The multiplexing capacity depends on the number of available isotopic and isobaric tagging combinations. Introduction of the TMTpro ${ }^{7}$, which is capable of tagging 16 samples in single experiment, can push the limits of cPILOT to 32-plex. cPILOT consists of multiple pipetting steps and requires extensive care and user skills to perform sample preparation. Even with an expert user, manual errors are inevitable, which invites the use of robotic platforms to process samples in the cPILOT strategy. Since cPILOT utilizes pH dependent tagging of the peptides, the $\mathrm{pH}$ needs to be maintained for the light and the heavy dimethylated set of samples. Mildly acidic-basic $\mathrm{pH}$ can result in dimethylation of both $\mathrm{N}$-termini and lysine residues. An advantage of cPILOT is that it requires only half of the isobaric 
tags since peptide $\mathrm{N}$-termini are occupied with the dimethyl groups. This affords a greater number of samples to be labelled at half the cost. Handling larger sample numbers requires that reagent exposure times are similar for the first and the last sample in a batch. A pipette dispenser that can accommodate up to 32 samples in parallel can best be achieved with the use of robotic liquid handling devices.

In order to process multiple samples by cPILOT, the manual workflow was amended to incorporate automation. The robotic liquid handler used in this study has two pods with 96-channel and 8-channel pipetting abilities, with a gripper to place the plates in the available 28 deck locations. The liquid handler is integrated with a positive pressure apparatus, orbital shaker, and a device to heat/cool samples in the 96 well plate. The positive pressure apparatus assists in performing buffer exchanges in the SPE plates during clean-up, while the orbital shaker helps to vortex/mix the samples. The robotic platform was programmed to aspirate and dispense buffers and samples to 96-well plates, incubate, vortex samples, and transfer plates. Liquids with different viscosities, such as acetonitrile and water, require specific pipetting considerations that can also be programmed into the method.

The cPILOT workflow, starting from protein quantification by BCA to labeling the peptides with isobaric tags (i.e., TMT), was performed on the liquid handler system. The complete protocol was scaled to use 96 deep well plates that can hold $2 \mathrm{~mL}$ per well. The buffers were prepared prior to the start of the experiment and added to the 96 well plate so as to allow parallel sample processing. In the present study, 22 workflow replicates of mouse liver homogenate were added to the deep well plates and taken through the CPILOT protocol. Finally, a single sample consisting of the 22-plex equimolar mouse liver tagged peptides was injected to the mass spectrometer. Reporter ion intensities corresponding to peptide abundances in the samples demonstrated that samples processed with the liquid handler have lower CVs than the manual protocol (data not shown). The robotic platform also greatly improved the reproducibility of sample processing. Reproducibility and robustness are very important factors while processing large numbers of samples. Pipetting errors can lead to complete mis-interpretation of the data and here the robotic platform provided low inter-sample variation. Also using the robotic platform for CPILOT reduced the time required to prepare samples. For example, after developing the automated method, it required $2.5 \mathrm{~h}$ to process 22 samples in comparison to $7.5 \mathrm{~h}$ for manual cPILOT. Experiments are on-going in our laboratory to further evaluate comparisons of the manual and automated cPILOT workflows. Based on previous reports from our laboratory, the CV\%'s of protein reporter ion intensities in the manual cPILOT were on average $20 \%$ with some outliers exceeding this value ${ }^{12}$.

cPILOT is a chemical derivatization strategy at the peptide level, that can be used for any sample type such as cells, tissues, and body fluids. cPILOT offers enhanced sample multiplexing and with the incorporation of automation can facilitate high-throughput sample multiplexing in proteomics. This throughput is necessary to further advance disease and biological understanding and biomarker discovery.

\section{Disclosures}

The authors have nothing to disclose.

\section{Acknowledgments}

The authors acknowledge Vanderbilt University Start-up Funds and NIH award (R01GM117191) to RASR. 


\section{References}

1. Diamandis, E. P. Mass spectrometry as a diagnostic and a cancer biomarker discovery tool: opportunities and potential limitations. Molecular and Cell Proteomics. 3 (4), 367-378 (2004).

2. Qian, W.-J., Jacobs, J. M., Liu, T., Camp, D. G., 2nd \& Smith, R. D. Advances and challenges in liquid chromatography-mass spectrometry-based proteomics profiling for clinical applications. Molecular and Cellular Proteomics. 5 (10), 1727-1744 (2006).

3. Arul, A. B., Robinson, R. A. S. Sample Multiplexing Strategies in Quantitative Proteomics. Analytical Chemistry. 91 (1), 178-189 (2019).

4. Everley, R. A., Kunz, R. C., McAllister, F. E., Gygi, S. P. Increasing Throughput in Targeted Proteomics Assays: 54-Plex Quantitation in a Single Mass Spectrometry Run. Analytical Chemistry. 85 (11), 5340-5346 (2013).

5. Shiio, Y., Aebersold, R. Quantitative proteome analysis using isotope-coded affinity tags and mass spectrometry. Nature Protocol. 1 (1), 139-145 (2006).

6. Gygi, S. P. et al. Quantitative analysis of complex protein mixtures using isotope-coded affinity tags. Nature Biotechnology. 17 (10), 994-999 (1999).

7. Thompson, A. et al. TMTpro: Design, Synthesis, and Initial Evaluation of a Proline-Based Isobaric 16-Plex Tandem Mass Tag Reagent Set. Analytical Chemistry. 91 (24), 15941-15950 (2019).

8. Frost D. C., Feng, Y., Li, L. 21-plex DiLue Isobaric Tags for High-Throughput Quantitative Proteomics. Anal. Chem. 92 12, 8228-8234 (2020).
9. Evans, A. R., Robinson, R. A. Global combined precursor isotopic labeling and isobaric tagging (CPILOT) approach with selective MS(3) acquisition. Proteomics. 13 (22), 3267-3272 (2013).

10. Robinson, R. A., Evans, A. R. Enhanced sample multiplexing for nitrotyrosine-modified proteins using combined precursor isotopic labeling and isobaric tagging. Analytical Chemistry. 84 (11), 4677-4686 (2012).

11. King, C. D., Dudenhoeffer, J. D., Gu, L., Evans, A. R., Robinson, R. A. S. Enhanced Sample Multiplexing of Tissues Using Combined Precursor Isotopic Labeling and Isobaric Tagging (CPILOT). Journal of Visual Experiments. 10.3791/55406 (123) (2017).

12. King, C. D., Robinson, R. A. S. Evaluating Combined Precursor Isotopic Labeling and Isobaric Tagging Performance on Orbitraps To Study the Peripheral Proteome of Alzheimer's Disease. Analytical Chemistry. (2020).

13. Evans, A. R., Gu, L., Guerrero, R., Jr., Robinson, R. A. Global cPILOT analysis of the APP/PS-1 mouse liver proteome. Proteomics \& Clinical Applications. 9 (9-10), 872-884 (2015).

14. Gu, L., Evans, A. R., Robinson, R. A. Sample multiplexing with cysteine-selective approaches: cysDML and cPILOT. Journal of American Society of Mass Spectrometer. 26 (4), 615-630 (2015).

15. Ting, L., Rad, R., Gygi, S. P., Haas, W. MS3 eliminates ratio distortion in isobaric multiplexed quantitative proteomics. Nature Methods. 8 (11), 937-940 (2011).

16. Frost, D. C., Rust, C. J., Robinson, R. A. S., $\mathrm{Li}$, L. Increased N,N-Dimethyl Leucine Isobaric Tag 
Multiplexing by a Combined Precursor Isotopic Labeling and Isobaric Tagging Approach. Analytical Chemistry. 90 (18), 10664-10669 (2018).

17. Gu, L., Robinson, R. A. High-throughput endogenous measurement of S-nitrosylation in Alzheimer's disease using oxidized cysteine-selective cPILOT. Analyst. 141 (12), 3904-3915 (2016).

18. Amin, B., Ford, K. I., Robinson, R. A. S. Quantitative proteomics to study aging in rabbit liver. Mechanisms of Ageing and Development. 187, 111227 (2020). 